\title{
Developing a Measurement Scale of the Use of Mobile Technologies in E-learning: A Structural Equation Model
}

\author{
Hale H. Turhangil Erenler \\ Baskent University, Ankara
}

\begin{abstract}
Keywords:

Mobile learning, E-

learning, Learning

Management System, SEM

Received

06 May 2018

Received in revised form

01 August 2018

Accepted

06 August 2018

Correspondence:

hhterenler@baskent.edu.tr

Researchers agree that mobile learning implementation requires new pedagogies and successful integration and implementation of technologies into learning needs to be wellplanned. In this context, this study first aimed to develop a use of mobile technologies measurement scale and then examined students' perceptions and opinions of using mobile technologies as part of the E-learning program with data from 786 students. Exploratory and confirmatory factor analyses were used to develop the measurement model; then the structural model for the research was tested using SEM. From the SEM analysis, with one dimension and ten variables, the scale was acceptable and the model explained 42.34 percent of the variance, which is indicative of medium explanatory power. Reliability for the scale was assessed using Cronbach's alpha, which was greater than .80 for Use of Mobile Phones in this study, thus the items were reliable. The results showed that most of the students used the latest smartphone technologies and they generally approved of using these as part of their E-learning program on Moodle learning management system.
\end{abstract}

CAIMI Journals

\section{Introduction}

The use of mobile devices has become more common and their use is becoming more appreciated in education. A smartphone is a multipurpose mobile device that can assist people in performing activities by accessing information through the internet. Mobile learning (M-learning) is a process of learning using handheld devices such as smart phones and tablets. Determining the best strategies for implementing mobile learning is an area that requires more attention. How can teachers integrate mobile learning into their classes and 
which strategies must be used is a topic that needs to be addressed (Shuler, Winters, \& West, 2012).

Since knowledge creation is supported through several means, the adoption of smartphones in learning will be an enhancing factor to motivate students' interactivity with learning materials. Through smartphones and other media, students will have opportunities to follow the online course, access learning materials, have chats with peers and the instructor (Anshari, Almunawar, Shahrill, Wicaksono, \& Huda, 2017). In this paper, the author develops a measurement scale and then identifies students' preferences, the challenges and possibilities of integrating mobile learning.

\section{Theoretical Background}

Mobile learning is a type of learning model using mobile technology (Yuen \& Yuen, 2008), while E-learning supports individual learning with various types of computer technologies (Clark \& Mayer, 2008; Horton, 2006) using systems such as learning management systems (LMS).

Effective learning is not guaranteed by simply owning mobile technologies. Teachers must have useful strategies to implement the course using smart phones (Christensen \& Knezek, 2017). Teacher willingness to implement mobile learning in their classes is an important factor for improving learning. The way students use mobile technologies to learn must involve in an instructional paradigm if they are expected to succeed. Successful integration and implementation of technologies requires a well-planned map. Researchers agree that mobile learning implementation requires new pedagogies to create learner-centered environments rather than trying to adapt old ones (Cochrane, 2014; Laurillard, 2013).

In M-learning, there are four types of learning approaches. Individualized learning allows students to learn at their own pace, situated learning is realized as students use mobile devices to learn within a real context, collaborative learning occurs when students use mobile devices to easily interact with each other and informal learning takes place when students learn out of class at their convenience.

There are many barriers and challenges in integrating the M-technologies into learning. Many are similar to the barriers to technology integration. Even though many teachers used to consider smart phones distruptors of the class environment, instructional benefits are now leading teachers to make use of them.

\section{Prior Studies}

Numerous research studies on the use of mobile technologies have been published (Anshari et al., 2017; Bogdanovic, Barac, Jovanic, Popovic \& Radenkovic, 2014; Cheon, Lee, Crooks, \& Song, 2012; Christensen \& Knezek, 2017; Clark \& Mayer, 2008; Horton, 2006; Joo, Kim, \& Kim, 2016; Shuler, Winters \& West, 2012; Wilcox, Thall, \& Griffin, 2016; Yuen \& Yuen, 2008).

Ninty-two percent of all students use internet during the day via a mobile device (Lenhart, 2015) which means they are able to learn anytime and anywhere (Traxler, 2009). According to Steel (2012), they can personalize their learning; Corbeil and Valdes-Corbeil (2007) point out that they can collaborate; and Sha, Looi, Chen and Zhang (2012) emphasize their ability to participate in self-regulated learning. These devices are portable and students can use them 
for learning by connecting online instantly, uploading and sharing files and accessing audio/video recordings.

Having many models for technology integration removes internal and external barriers and increases usage and skills, thus building towards desirable goals (Vannatta \& Fordham, 2004). Teacher characteristics such as will and skill further lead to success according to McCombs and Marzano (1990).

Wilcox, Thall and Griffin (2016) found that most students access LMS platforms on their smartphones, whereas instructors use a desktop or laptop. The LMS they use, Canvas, is accessible on a cell phone but its mobile interfaces and features are different from the computer-based version. Files and modules are not organized as seen in the computer version so students cannot view them as their instructors intended, which is counterproductive.

Anshari et al. (2017) found that students use their smartphones as learning aids to access teaching materials or supporting information for various reasons. In addition to being convenient and portable and environmentally friendly, they enable comprehensive learning experiences, multi sourcing and multitasking. Students also use smartphones to interact with teachers outside class and manage their group assignments. The challenges were distraction, dependency, lack of hands-on skills, and the reduced quality of face-to-face interaction. They argued that to avoid any disturbances when using smartphones within a classroom environment, proper rules for use should be established before teaching begins.

Although smartphones can be used anytime and anywhere for learning, mobile devices have limited use as a tool for supporting teaching and learning on campus. Joo, Kim and Kim (2016) found that students use the devices only when their instructors encourage them and generally in-class use is not allowed because of potential distractions. A second finding is that the academic use of such devices to access instructional materials is not yet ingrained and finally students cannot use their mobile devices for LMS. The authors indicated that today's college students want a mobile-friendly LMS experience and highly personalized guidance for meaningful learning on their handheld mobile device; which means that a new type of LMS for mobile learning, i.e., a mobile learning management system (m-LMS) is necessary.

In their paper, Cheon, Lee, Crooks and Song (2012) explained how college students' beliefs influence their willingness to adopt the use of mobile devices in their coursework. They found that attitude, subjective norm, and behavioral control positively influenced students' intention to adopt mobile learning.

The goal of this study was first to develop a measurement scale for the use of mobile technologies and then to examine students' perceptions or opinions of using mobile technologies as part of the E-learning program on Moodle LMS. In order to decide the best way to adapt to the LMS, it was necessary to determine which technologies they use to access the course materials, how they are used, what problems they had and what contribution they made to the learning process. The study is guided based on the following questions:

1) What were the perceptions of students' use of mobile technologies?

2) What were the advantages and what were the problems students faced?

3) What were the best practices for using mobile technologies?

4) What were the strategies for adopting mobile technologies into learning? 


\section{Methodology \\ Research Model}

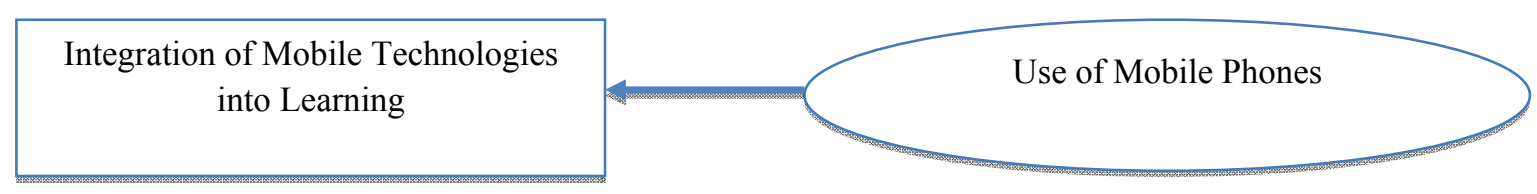

Figure 1. Research model

\section{Hypothesis Development}

As presented in Figure 1, this study used a model based on previous literature on the infrastructure of mobile technologies and students' habits when using them (Bogdanovic et al., 2014). Thus, a hypothesis is developed as follows:

1. Use of Mobile Phones: Students should use their mobile devices often to be familiar with the technology.

Hypothesis: Use of mobile phones is positively associated with the integration of $\mathrm{M}$ technologies.

\section{Research Setting}

The data were collected at a funded university in Ankara, the capital of Turkey. This university had already started to conduct an online computer literacy course with E-learning methods in a learning management system (LMS) Moodle. The course was offered in 23 sections to all of the students in the university excluding engineering students starting in the 2016-2017 academic calendar year. Lecturers were encouraged to use LMS Moodle in their classes. The teaching materials, course syllabus and all other digital course materials such as videos, pdf documents and presentations were prepared by the E-learning team in the university and uploaded for instructors in a standardized framework.

\section{Participants}

This first year service course was compulsory for all students during either the fall or spring semester. The number of students registered during the 2017 spring semester was 1976 and 786 students answered the online survey questionnaire resulting in a response rate of 39.78 .

In order for M-learning to succeed as part of an E-learning program, it is necessary to determine the factors that university students consider important in the integration of $\mathrm{M}$ learning - their interest in using mobile technologies for learning, their experience with the technology, and the technical capacity and characteristics of their mobile devices (Bogdanovic et al., 2014).

Table 1 summarizes the demographics and background information of the respondents and Table 2 presents students' experience with E-learning platforms and their computer skills levels. There were more women than men since only one fourth of the 786 students were men (205 men versus 581 women). All respondents were undergraduate students, and their ages ranged from 18 to 24 . 
Table 1

Demographics of Survey Participants

\begin{tabular}{|c|c|c|}
\hline Measure and Item & Frequency & Percentage \\
\hline $\begin{array}{l}\text { Gender } \\
\text { Female } \\
\text { Male }\end{array}$ & $\begin{array}{l}581 \\
205\end{array}$ & $\begin{array}{l}73.9 \\
26.1\end{array}$ \\
\hline \multicolumn{3}{|l|}{ Age } \\
\hline 18 & 203 & 25,8 \\
\hline 19 & 185 & 25.5 \\
\hline 20 & 209 & 26.6 \\
\hline 21 & 114 & 14.5 \\
\hline 22 & 38 & 4.8 \\
\hline 23 & 22 & 2.8 \\
\hline$>=24$ & 15 & 1.9 \\
\hline $\begin{array}{l}\text { Faculty } \\
\text { Faculty of Dentistry } \\
\text { Faculty of Medicine }\end{array}$ & $\begin{array}{l}45 \\
30\end{array}$ & $\begin{array}{l}5.7 \\
3.8\end{array}$ \\
\hline Faculty of Education & 75 & 9.5 \\
\hline Faculty of Science and Letters & 35 & 4.4 \\
\hline Faculty of Fine Arts, Design and Architecture & 35 & 4.4 \\
\hline Faculty of Law & 47 & 5.9 \\
\hline Faculty of Economics and Administrative Sciences & 78 & 9.9 \\
\hline Faculty of Communications & 35 & 4.4 \\
\hline Faculty of Health Sciences & 35 & 4.4 \\
\hline Faculty of Commercial Sciences & 62 & 7.8 \\
\hline Vocational School of Social Sciences & 75 & 9.5 \\
\hline Vocational School of Health Sciences & 74 & 9.4 \\
\hline Vocational School of Technology & 6 & 0.7 \\
\hline Adana Vocational School of Health Sciences & 49 & 6.2 \\
\hline Kazan Vocational School & 50 & 6.3 \\
\hline Konya Vocational School of Health Sciences & 37 & 4.7 \\
\hline State Conservatory & 18 & 2.3 \\
\hline \multicolumn{3}{|l|}{ Prep Student } \\
\hline Yes & 71 & 10.1 \\
\hline No & 165 & 89.9 \\
\hline
\end{tabular}

Table 2

Background of the Survey Participants

\begin{tabular}{lccccc}
\hline Measure and Item & Frequency & Percentage & Measure and Item & Frequency & Percentage \\
\hline $\begin{array}{l}\text { Prior Experience } \\
\text { Moodle }\end{array}$ & with LMS & & Computer Skills & & \\
$\quad$ None & 425 & 54.1 & Beginner & 135 & 14.8 \\
& & & & 573 & 73.3 \\
Class & 214 & 27.1 & Intermediate & 78 & 11.9 \\
2 Classes & 65 & 8.5 & Advanced & & \\
3 Classes & 48 & 6.0 & & & \\
$>=4$ Classes & 34 & 4.3 & & & \\
& & & & & \\
\hline
\end{tabular}




\section{Instrument}

The data tool items were adapted based on previous literature on infrastructure and the students' habits in using mobile technologies (Bogdanovic et al., 2014). A 5-point Likert scale questionnaire ranging from 1 (strongly disagree) to 5 (strongly agree) was used for the measurement. The scale was studied and its content and structure were reviewed by a colleague. The questionnaire was delivered at the end of the semester. Table 3 summarizes the measurement constructs and codes used in this study.

Table 3

Variable Definitions and Measurements

\begin{tabular}{ll}
\hline Measurement Construct & Variable Codes Cronbach's Alpha \\
\hline & U1 \\
U2 & U3 \\
Use of mobile phones & U5 \\
& U6 \\
U7 & U8 \\
U9 \\
U10 \\
U11 \\
U12 \\
U13 \\
U14 \\
\hline
\end{tabular}

\section{Pilot Test}

An online pilot test was conducted at the end of the spring semester of 2017 with a class of 100 computer literacy students who followed the course with E-learning methods and according to the results there had been no change in the scale items. The pilot test results were excluded from the actual study.

\section{Data Analysis}

This study used a structural equation modeling (SEM) for data analysis. SEM analysis was chosen over regression analysis because SEM can be used to analyze all the paths in one analysis. First, exploratory and then confirmatory factor analyses were used to develop the measurement model. To explore the causal relationships among all constructs, the structural model for the research model depicted in Figure 1 was tested using SEM. The statistical analysis software packages used to perform the analysis were SPSS AMOS 23.0 and SPSS Statistics 23.0.

\section{Measurement Model}

The measurement model was assessed in terms of individual item loadings, reliability of measures and internal validity. Reliability was assessed using Cronbach's Alpha. When Cronbach Alpha is equal to or greater than .60, the measurement's internal validity is high (Malhotra, 1999; Nunnally, 1978). In Table 3, the value is greater than .80 for the Use of Mobile Phones, which shows that the items are reliable and the features that need to be measured are correct. 
Before testing the hypothesis with a structural equation model, the exploratory factorial analysis was performed to determine the measurement size used in the model. The criteria of $\mathrm{KMO}>.50$ shows whether the sample size is adequate for factorial analysis and the value for $\chi_{2}$ is significant (Tabachnick \& Fidell, 2001). This means that the sample size used in this study was adequate. The values in Table 4 show that the data was appropriate for exploratory factor analysis.

At the end of the implemented exploratory factor analysis, factors need to be greater than 1 and the factor values of constructs must be greater than .5 in order to find the most convenient solution (Tabachnick \& Fidell, 2001). For this reason, constructs with factor values $<.50$ have been excluded from the analysis. The results are shown in Table 4.

Table 4

Exploratory Factor Analysis Results (KMO =.858; Barlett's Sph $\left.\chi^{2}=2696,314 ; p=.000\right)(V E=\% 42,349 ; \alpha$ $=4.235$ )

Use of Mobile Phones

U3- Do you use a mobile phone for e-mails?

U4- Do you use a mobile phone for web surfing?

U5- Do you use a mobile phone for downloading images?

U7- Do you use a mobile phone for viewing videos?

U8- Do you use a mobile phone for downloading videos?

U9- Do you use a mobile phone for payments?

U10- Do you make video calls?

U11- Do you use GPS on your mobile phone?

U12- Do you use audio recordings?

U13- How often do you install applications on your mobile phone

\section{Structural Model}

The structural equation model with one factor-dimension (F1: Use of Mobile Phones) and its variables are shown in Figure 2. Before evaluating the relationships between the structural equation model and the research model, it is necessary to determine that the model is statistically valid. Goodness of Fit Index (GFI), Adjusted Goodness of Fit Index (AGFI), Normed Fit Index (NFI), Relative Fit index (RFI), Incremental Fit index (IFI), Tucker-Lewis index (TLI), Comparative Fit Index (CFI) and Root Mean Square Error Approximation (RMSEA) values are shown in Table 5.

Table 5

Measurement Model's Goodness of Fit values

\begin{tabular}{lll}
\hline Measures & Research Model & Ideal Model \\
\hline$p$ & .000 & $>.05$ \\
$\chi 2 /$ sd (CMIN/DF) & 8.80 & $<5$ \\
Goodness of Fit Index (GFI) & .93 & $>.90$ \\
Adjusted Goodness of Fit Index (AGFI) & .89 & $>.85$ \\
Normed Fit Index (NFI) & .89 & $>.90$ \\
Relative Fit Index (RFI) & .85 & $>.90$ \\
Incremental fit index (IFI) & .90 & $>.90$ \\
Tucker-Lewis index (TLI) & .86 & .90 \\
Comparative Fit Index (CFI) & .90 & $>.90$ \\
Root Mean Square Error Approximation (RMSEA) & .10 & $>.08$ \\
Hoelter .05 Index (HFIVE) & 129 & \\
Hoelter.01 Index (HONE) & 148 & $>.10$ \\
Standardized Root Mean Square Residual (SRMR) & .05 & \\
\hline
\end{tabular}

According to the results in Table 5, the value obtained by the $\chi^{2}$ value divided by the degrees of freedom is equal to 8.80 . When this value is between 0 and 3 , the data and model are valid. 
When this value is equal to or less than 5 it is still acceptable (Hooper, Coughlan, \& Mullen, 2008). Since the $\chi 2$ value is sensitive to sample size, other measures related to the structural equation model were also studied. According to this, the other measures (GFI $=.93$; AGFI $=$ $.89 ; \mathrm{NFI}=.89 ; \mathrm{RFI}=.85 ; \mathrm{IFI}=.90 ; \mathrm{TLI}=.86 ; \mathrm{CFI}=.90)$ are generally within acceptable values. When the values are close to 1.0 , it shows that the data is generally acceptable for the model. According to those criteria, the data is compatible with the research model. Moreover, the RMSEA value, which must be between .05 and .10, was found to be .1 . According to the RMSEA value, it can be said that the data is compatible with the research model. These results show that the sample size is adequate for the research model, and the model is significant and valid statistically.

According to the Hoelter (1983) .05 index, the minimum sample size is 129 to test research hypotheses at the .05 significance level, whereas for the Hoelter (1983) .01 index, the minimum sample size is 148 to test research hypotheses at the .01 significance level. Our sample size to test the research hypothesis is larger than the minimum required sample size. The structural equation model obtained by required modifications is shown in Figure 2, in which the arrows show the relationships between variables and double-sided relationships between the error terms of the questions "U4", "U7", "U9" and "U11". The values on those arrows are the standardized regression weights as shown in Table 6.

Table 6

Standardized Regression Weights

\begin{tabular}{|c|c|c|c|}
\hline & & & Standardized Regression Weights \\
\hline $\mathrm{U3}$ & $\leftarrow$ & Use of mobile phones & $.57 * * *$ \\
\hline $\mathrm{U} 4$ & $\leftarrow$ & Use of mobile phones & $.54 * * *$ \\
\hline U5 & $\leftarrow$ & Use of mobile phones & $.66 * * *$ \\
\hline U7 & $\leftarrow$ & Use of mobile phones & $.63 * * *$ \\
\hline U8 & $\leftarrow$ & Use of mobile phones & $.55^{* * *}$ \\
\hline U9 & $\leftarrow$ & Use of mobile phones & $.49 * * *$ \\
\hline U10 & $\leftarrow$ & Use of mobile phones & $.70 * * *$ \\
\hline U11 & $\leftarrow$ & Use of mobile phones & $.62 * * *$ \\
\hline U12 & $\leftarrow$ & Use of mobile phones & $.61 * * *$ \\
\hline U13 & $\leftarrow$ & Use of mobile phones & $.47 * * *$ \\
\hline
\end{tabular}

Reliability was assessed using the internal validity measure, Cronbach's alpha. In Table 7 , the values are greater than .80 , which shows that the items are reliable and the features that need to be measured are correct.

Table 7

Measurement Reliability

\begin{tabular}{lcc}
\multicolumn{2}{c}{ Corrected Item-Total Correlation } & Cronbach's Alpha if Item Deleted \\
\hline U3 & .53 & .82 \\
U4 & .51 & .82 \\
U5 & .60 & .81 \\
U7 & .60 & .82 \\
U8 & .49 & .83 \\
U9 & .46 & .83 \\
U10 & .63 & .81 \\
U11 & .58 & .82 \\
U12 & .54 & .82 \\
U13 & .43 & .83 \\
\hline
\end{tabular}

Figure 2 shows the standardized coefficients for each hypothesized path in the model and the $\mathrm{R}^{2}$ for each dependent variable. The new model explains 42.34 percent of the variance, 
which is indicative of medium explanatory power.

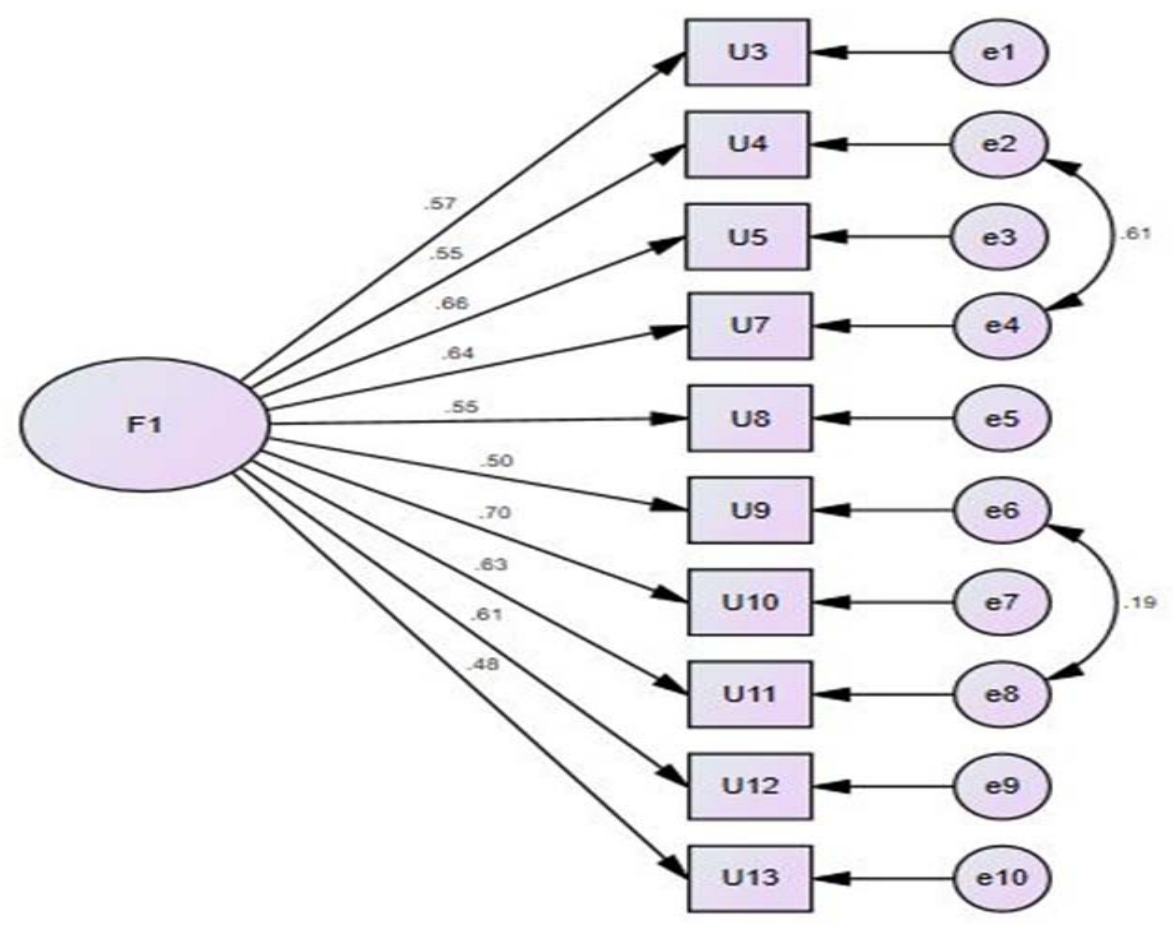

Figure 2. One dimensional confirmatory factor analysis (CFA) model

\section{Discussion}

This study aimed to develop a measurement scale for the use of the mobile technologies as part of an E-learning program on Moodle learning management system in a computer literacy course at a funded University in Turkey. The model was based on previous literature on infrastructure and students' habits regarding the use of mobile technologies (Bogdanovic et al., 2014). From the SEM analysis, with one dimension and ten variables, the scale was acceptable and the model explains 42.34 percent of the variance which is indicative of medium explanatory power.

Other aspects such as technical characteristics, use of mobile phones in education, problems and students' opinions of using mobile devices in the questionnaire have also been taken into consideration in analyzing students' perceptions, problems and challenges in using the mobile technologies as part of their learning.

The results showed that most of the students used the latest smartphone technologies and their multimedia features such as audio-video downloading, sending e-mails and browsing through the internet. $62 \%$ of the students accessed the learning management system Moodle and $32 \%$ of the students accessed Adobe Connect video conference system while $78 \%$ of the students accessed other educational materials using their smartphones. They generally approved of using these as part of their E-learning program on a Moodle learning management system and approximately $80 \%$ of the students think that using mobile technologies and accordingly mobile activities contribute to their learning. Moreover, using such technologies did not create any serious technical or other problems. The main task for the students was learning and mobile learning can be challenging since it has many 
components such as platform, course, and content coming from different sources: authors, instructors, and developers.

The study also showed that the integration of mobile technologies to learning will be an enhancing factor to increase students' interactivity with learning materials, instructors and the learning environment, which will contribute to students' learning. The results provide valuable implications for ways to increase college students' acceptance and integration of mobile learning.

This research found that some of the key issues to be addressed in terms of adapting course design for mobile technologies as part of learning management systems were:

A mobile application for LMS must be created on mobile devices,

1) The delivery platform must be adapted to mobile devices,

2) Course content, tests and learning activities must be designed to integrate with mobile devices,

3) Instructional content and mobile learning environment must be compatible with small screen with low resolution display, slow network pace and navigation problems (micro lecture and audio format lecture),

4) Instructional design models, techniques and strategies must be used.

5) The quality of learning should not suffer due to the change in delivery mode.

\section{Implications}

In this study, first exploratory and confirmatory factor analyses were used to develop the measurement model; then the structural model for the research was tested using SEM. From the SEM analysis, with one dimension and ten variables, the scale was found acceptable and the model explains 42.34 percent of the variance, which is indicative of medium explanatory power. Reliability for the scale was assessed using Cronbach's alpha which is greater than .80 for the Use of Mobile Phones. The items were reliable.

The results showed that most of the students used the latest smartphone technologies and they generally felt positively about using these as part of their E-learning program on a Moodle learning management system. The quality and the structure of the system for both E-learning and M-learning must facilitate student use of the contents. Planning needs to be given importance and strategies must be applied.

Technologies should not be seen only as technological tools but also as an important part of learning practices. Therefore, the pedagogical effectiveness of the platforms will ensure that they are successful and widely accepted.

The findings of this research will be valuable for both academics and practitioners of Elearning systems. .

\section{Limitations of the Study}

In this study, the main limitation was that the population was limited to freshman students who enrolled in the computer literacy course at the university and the sample was limited to the students who chose to complete the survey. The study assumed that the respondents answered all survey questions honestly. This model should be tested with respect to other LMS courses at the university. Therefore, further research is necessary. 


\section{References}

Anshari, M., Almunawar, M., Shahrill, M., Wicaksono, D., \& Huda, M. (2017). Smartphones usage in the classrooms: Learning aid or interference? Education Information Technology, 22(6), 3063-3079. doi:10.1007/s10639-017-9572-7

Bogdanovic, Z., Barac, D., Jovanic, B., Popovic, S., \& Radenkovic, B. (2014). Evaluation of mobile assessment in a learning management system. British Journal of Educational Technology, 231-244. doi:10.1111/bjet.12015

Cheon, J., Lee, S., Crooks, S., \& Song, J. (2012). An investigation of mobile learning readiness in higher education based on the theory of planned behavior. Computers \& Education, 59, 1054-1064.

Christensen, R., \& Knezek, G. (2017). Readiness for integrating mobile learning in the classroom: Challenges, preferences and possibilities. Computers in Human Behavior, 76, 112-121. doi:http://dx.doi.org/10.1016/j.chb.2017.07.014

Clark, R., \& Mayer, R. (2008). E-learning and the science of instruction: Proven guidelines for consumers and designers of multimedia learning. San Francisco, CA: Pfeiffer.

Cochrane, T. D. (2014). Critical success factors for transforming pedagogy with mobile Web 2.0. British Journal of Educational Technology, 45(1), 65-82.

Corbeil, J. R., \& Valdes-Corbeil, M. E. (2007). Are you ready for mobile learning? Educause Quarterly, 30(2), 51-58.

Hoelter, J. W. (1983). The analysis of covariance structures: Goodness-of-fit indices. Sociological Methods \& Research, 11(3), 325-344.

Hooper, D., Coughlan, J., \& Mullen, M. (2008). Structural equation modelling: Guidelines for determining model fit. Electronic Journal of Business Research Methods, 6(1), 53-60

Horton, W. (2006). E-learning by design. San Francisco, CA: Pfeiffer.

Joo, Y., Kim, N., \& Kim, N. (2016). Factors predicting online university students' use of a mobile learning management system (m-LMS). Education Technology Research Development, 64, 611-630. doi:10.1007/s11423-016-9436-7

Laurillard, D. (2013). Teaching as a design science: Building pedagogical patterns for learning and technology. New York: Routledge.

Malhotra, N. (1999). Marketing research: An applied orientation (3 ed.). Upper Saddle River New Jersey: Prentice Hall.

McCombs, B. L., \& Marzano, R. J. (1990). Putting the self in self-regulated learning: The self as agent in integrating will and skill. Educational psychologist, 25(1), 51-69.

Nunnally, J. (1978). Psychometric theory (2nd ed.). New York: McGrawHill.

Sha, L., Looi, C. K., Chen, W., \& Zhang, B. H. (2012). Understanding mobile learning from the perspective of self-regulated learning. Journal of Computer Assisted Learning, 28(4), 366-378.

Shuler, C., Winters, N., \& West, M. (2012). The future of mobile learning: Implications for policy makers and planners. France: United Nations Educational, Scientific and Cultural Organization

Steel, C. (2012). Fitting learning into life: Language students' perspectives on benefits of using mobile apps. In M. Brown, M. Hartnett, \& T. Stewards (Eds.), Ascilite 2012: Future challenges, sustainably futures (pp. 875-880). New Zealand: Wellington.

Tabachnick, B., \& Fidell, L. (2001). Using multivariate statistics (4 ed.). MA: Allyn \& Bacon, Inc.

Traxler, J. (2009). Current state of mobile learning. Mobile learning: Transforming the delivery of education and training. International Review on Research in Open and Distance Learning, 8(2), 9-24.

Vannatta, R. A., \& Nancy, F. (2004). Teacher dispositions as predictors of classroom technology use. Journal of Research on Technology in Education, 36(3), 253-271

Wilcox, D., Thall, J. \& Griffin, O. (2016). One canvas, two audiences: how faculty and students use a newly adopted learning management system. In G. Chamblee \& L. Langub (Eds.), Proceedings of Society for Information Technology \& Teacher Education International Conference (pp. 1163-1168). Savannah, GA, United States: Association for the Advancement of Computing in Education (AACE).

Yuen, S., \& Yuen, P. (2008). Mobile Learning. In L. Tomei (ed.), Encyclopedia of Information Technology Curriculum Integration (pp. 580-586). IGI Global, Hershey, PA: Idea Group. 